\title{
Oviposition site preference of the bamboo gall maker, Aiolomorphus rhopaloides (Hymenoptera: Eurytomidae), on bamboo in terms of plant-vigor hypothesis
}

\author{
Ei'ichi SHIBATA* \\ Laboratory of Forest Protection, Graduate School of Bioagricultural Sciences, Nagoya University; Nagoya 464-8601, Japan
}

(Received 19 March 2005; Accepted 19 July 2005)

\begin{abstract}
Oviposition site preference of the bamboo gall maker, Aiolomorphus rhopaloides Walker, was investigated in a bamboo stand in terms of plant-vigor hypothesis. Galls in branches were distributed contagiously due to the difference in branch length. More galls were found on longer branches. Survival rates within galls, nitrogen content and gall size did not differ with branch-length class, suggesting that oviposition preference on longer branches is not attributed to better progeny fitness. The phenology of the buds where females oviposit and the greater number of buds on longer branches might contribute to female oviposition site preference.
\end{abstract}

Key words: Aiolomorphus rhopaloides; bamboo; gall maker; oviposition site preference; Phyllostachys heterocycla

\section{INTRODUCTION}

Female gall insects lay their eggs in plant tissues, and galls are formed by the stimulus caused by oviposition stimuli and/or the result of larval feeding (Price et al., 1987). Because the larvae of gall insects cannot exit the host gall during their development, the eventual performance can be more affected by the host conditions than the performance of free-living insects. In other words, the oviposition sites may be very important for gall insects, and the distribution of galls may affect the performance in subsequent developmental stages.

Price et al. (1995) emphasized the importance of a link between oviposition preference and offspring performance in population studies, especially of gall-forming sawflies. Price (1991) proposed a plant-vigor hypothesis in which female galling insects select relatively large modules on which the larvae survive better; plant individuals from nutrient-rich environments are used more frequently than plant individuals from low-resource habitats. However, Rehill and Schultz (2001) tested the plant-vigor hypothesis by determining the distribution of galls formed on leaves of witch hazel, Hamamelis virginiana, by the aphid, Hormaphis hamamelidis, and demonstrated that the average number of galls per leaf was not related to the mean leaf size, contrary to the preference prediction of the plant-vigor hypothesis.

The bamboo gall maker, Aiolomorphus rhopaloides Walker (Hymenoptera: Eurytomidae), causes galls on two species of bamboo, Phyllostachys heterocycla Matsumura and P. bambusoides Siebold and Zuccarini (Monocotyledoneae: Gramineae) in Japan (Takahashi and Mizuta, 1971; Kobayashi, 1994; Yukawa and Masuda, 1996). This species of gall maker is univoltine; adult females emerge from galls from mid-April to early May (Shibata, 2001; Shibata and Ito, 2005) and oviposit in the young buds of bamboo branchlets, which develop into unitary galls (length: $20-30 \mathrm{~mm}$, width: 2-4 mm) (Takahashi and Mizuta, 1971). Outbreaks of $A$. rhopaloides occasionally occur in stands of $P$. heterocycla in west Japan (Kobayashi, 1994). This study examines how $A$. rhopaloides oviposits in a bamboo stand in terms of the plant-vigor hypothesis. On the basis of the distribution of galls, survival rates within galls and gall size in terms of performance are evaluated with branch length, bud nitrogen levels, and bud length as proximate factors.

* E-mail: shibatae@agr.nagoya-u.ac.jp

DOI: 10.1303/aez.2005.631 


\section{MATERIALS AND METHODS}

Study stand. This study was conducted in a stand of $P$. heterocycla with an area of ca. $400 \mathrm{~m}^{2}$ in Nagoya City, central Japan. Mean diameter at breast height (dbh) and height were $4.5 \pm 0.8 \mathrm{~cm}$ (mean $\pm \mathrm{SD}$ ) and $7.2 \pm 0.9 \mathrm{~m}$, respectively.

Methods. In mid-March 1999, five bamboo culms were cut at random just before gall-maker emergence. All branches were clipped from each culm after measuring the height of the base of each branch from the ground. After the branch lengths were measured and the number of galls on each branch was counted, the galls were collected and put in individual test tubes (diameter: $1 \mathrm{~cm}$, length: $7 \mathrm{~cm}$ ) kept outdoors at ambient temperatures. Emerged gall makers were counted every $2-3 \mathrm{~d}$ until mid-July. After the emergence of the $A$. rhopaloides females, the diameter of the central part of each gall from which $A$. rhopaloides emerged was measured using venier calipers.

To determine the relationship between branch length and bud number, five bamboo culms were cut in late May 1998 and 10 branches were cut from each of the five culms at random. After measuring the branch length, the number of buds on each branch was counted.

To evaluate the nutritional conditions of the bamboo buds, eight bamboo culms were selected and eight branches of each culm were cut on 13 May and 1 July 1998. After measuring each branch length, each bud on each branch was put in an envelope and then dried $\left(80^{\circ} \mathrm{C}\right.$ for $\left.3 \mathrm{~d}\right)$. The total nitrogen content in each bud was determined using a C-N analyzer (MT-1600, Yanako, Tokyo, Japan).

Statistical analyses. Statistical analyses were performed using the SPSS computer program (Norussis, 1993). Three-way ANOVA was used to detect significant differences in gall numbers on branches per 10-cm branch length (transformed to $\log [x+1])$ among culms, among height classes and among branch length classes. Differences in branch number (transformed to $\log [x+1]$ ), in branch length and in number of young buds (transformed to $\log [x+1])$ among height classes were detected by one-way ANOVA with Tukey's HSD multiple test. One-way ANOVA with Tukey's HSD multiple test was used to determine differences in gall numbers per $10-\mathrm{cm}$ branch length (transformed to $\log [x+1])$, in percentages of buds observed with galls (transformed to arcsine) and in survival rates (transformed to arcsine) among branch-length classes. The $F$-test was used to determine differences in bud length and in nitrogen content (transformed to arcsine) between dates. The Pearson correlation coefficient $\left(r^{2}\right)$ was applied to the relationships between branch length and bud length, between branch length and nitrogen content, and between branch length and gall size. The spatial distribution pattern of galls on each branch was analyzed using Morisita's $I_{\delta}$ index (Morisita, 1959).

\section{RESULTS}

\section{Bamboo module structure and vertical distribu- tion of galls}

Significant differences were detected in the mean number of branches for height classes $(F=4.71, \quad \mathrm{df}=7, \quad p=0.01)$. There were more branches at heights of $2-7 \mathrm{~m}$ than $<2 \mathrm{~m}$ and $>7 \mathrm{~m}$ (Fig. 1a). The mean branch length differed significantly among height classes $(F=37.15, \mathrm{df}=7$, $p<0.001)$. Branches were longer at heights of $2-5 \mathrm{~m}$ than at $<2 \mathrm{~m}$ and at $>5 \mathrm{~m}$ (Fig. 1b). Branch length and bud number formed an exponential curve ( $x$ : branch length, $y$ : bud number, $n=50$, $\left.y=5.89 x^{0.0281}, r^{2}=0.779\right)$ and the mean bud number per branch estimated from this relationship differed significantly among height classes $(F=36.93$, $\mathrm{df}=7, p<0.001)$. There were more buds at heights of 2-6m than at $<2 \mathrm{~m}$ and at $>6 \mathrm{~m}$ (Fig. 1c). There was a significant difference in the number of galls per $10-\mathrm{cm}$ branch length among height classes $(F=2.49, \mathrm{df}=7, p=0.019)$ with more galls at heights of $2-8 \mathrm{~m}$ than at $<2 \mathrm{~m}$ and at $>8 \mathrm{~m}$ (Fig. 1d). Three-way ANOVA on the mean number of galls showed significant interactions between culm and height, and between height and branch length, but not between culm and branch length (Table 1). This suggests that branch length on which galls are abundant is similar in every culm. Consequently, I combined data on branch length for all culms.

\section{Gall spatial distribution pattern}

The index of spatial distribution, $I_{\delta}$, was 2.36 ( $F=919.2, p<0.001)$, indicating that bamboo galls are contagiously distributed on the bamboo branches. 

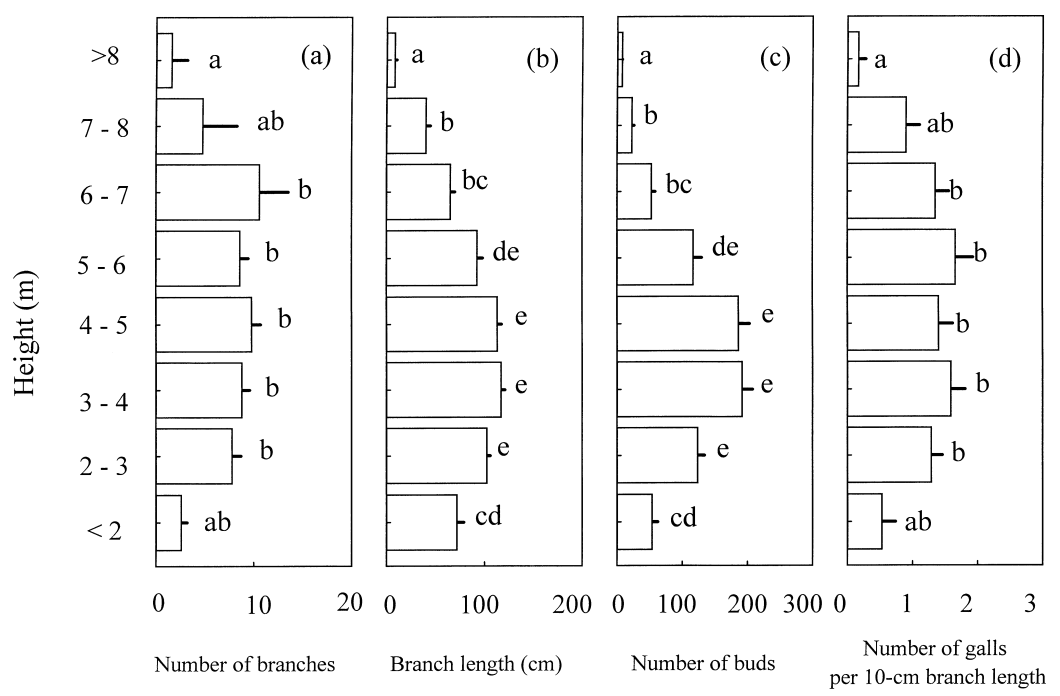

Fig. 1. Mean number of branches (a), mean branch length (b), mean number of buds (c), and mean number of galls per 10-cm branch length (d) at each bamboo height. Horizontal lines show + SE. Different letters show significant differences $(p<0.05)$.

Table 1. Three-way ANOVA of mean number of galls per 10-cm branch length for culm, height class and branch length class

\begin{tabular}{lrrrr}
\hline \multicolumn{1}{c}{ Source } & df & Mean square & \multicolumn{1}{c}{ F } & \multicolumn{1}{c}{$p$} \\
\hline Culm & 4 & 0.940 & 88.962 & 0.001 \\
Height & 7 & 0.013 & 1.261 & 0.273 \\
Branch length & 7 & 0.023 & 2.163 & 0.039 \\
Culm $\times$ Height & 20 & 0.029 & 2.708 & 0.001 \\
Culm $\times$ Branch length & 24 & 0.009 & 0.845 & 0.026 \\
Height $\times$ Branch length & 25 & 0.018 & 1.699 & 0.458 \\
Culm $\times$ Height $\times$ Branch length & 15 & 0.011 & 0.999 & \\
Error & 170 & 0.011 & & \\
Total & 276 & & & \\
\hline
\end{tabular}

\section{Number of galls per $10-\mathrm{cm}$ branch length in branch-length class}

The mean number of galls per $10-\mathrm{cm}$ branch length differed significantly among branch-length classes and increased as branch length increased $(F=14.62, \mathrm{df}=7, p<0.001)$ (Fig. 2a).

\section{Percentage of galled buds for branch length}

There was a significant difference in the proportion of galled buds among branch length classes with more galled buds at lengths of $40-60 \mathrm{~cm}$ $(F=2.45, \mathrm{df}=7, p=0.019)$ (Fig. 2b).

\section{Survival rate in branch-length class}

The survival rate was not significantly different among branch-length classes $(F=0.46, \mathrm{df}=7, p=$ 0.861) (Fig. 2c).

\section{Bud elongation}

A significant difference in bud length was detected between 13 May $(2.70 \pm 0.47 \mathrm{~cm})$ and 1 July $(2.97 \pm 0.09 \mathrm{~cm})(F=21.01, \mathrm{df}=1, p<0.001)$. Significant correlations were detected between branch length and bud length on 13 May and on 1 July (13 May: $n=64, r^{2}=0.233, p<0.001,1$ July: $n=64$, $r^{2}=0.115, p<0.05$ ) (Fig. 3a). However, bud length tended to be constant on 1 July (Fig. 3a).

\section{Bud nutrition}

On 13 May and 1 July, there was a significant difference in bud nitrogen content (13 May: $3.25 \pm 0.50 \%$, 1 July: $2.35 \pm 0.49 \%) \quad(F=196.35$, $\mathrm{df}=1, p<0.001)$. No significant correlations were found between branch length and nitrogen content on 13 May and on 1 July (13 May: $n=120$, $r^{2}=0.001, p>0.05,1$ July: $n=124, r^{2}=0.052$, 

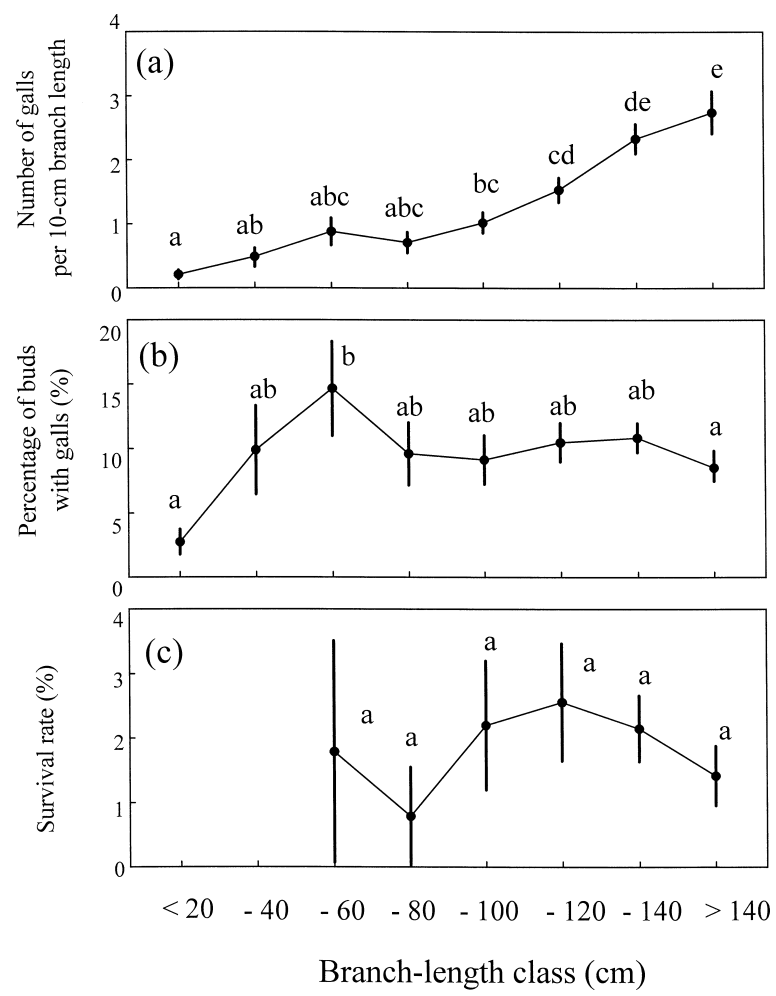

Fig. 2. Mean number of galls per $10-\mathrm{cm}$ branch length (a), mean percentage of buds with gall (b), and mean survival rate within galls (c) in each branch-length class. Vertical lines show \pm SE. Different letters show significant differences $(p<0.05)$.

$p>0.05)$ (Fig. 3b).

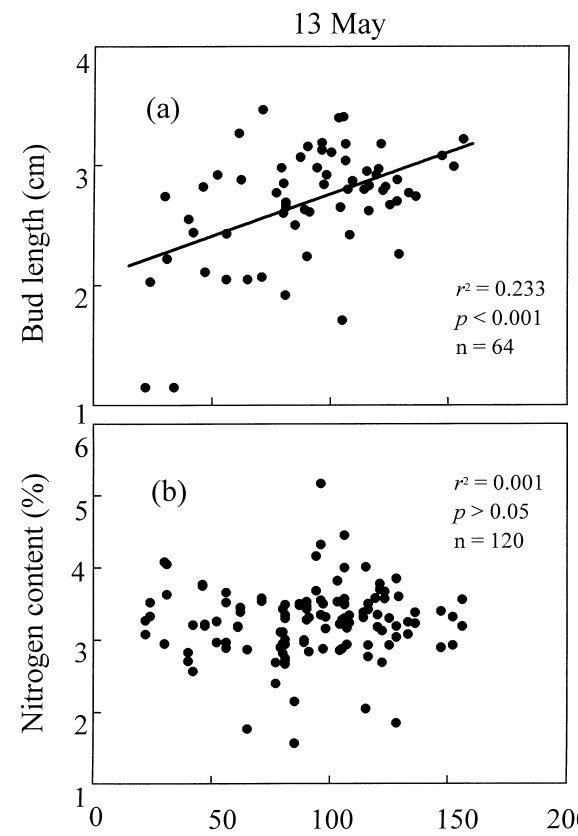

\section{Relationship between branch length and gall size}

There was no significant correlation between branch length and gall size $\left(n=21, r^{2}=0.027\right.$, $p>0.05$ ) (Fig. 4).

\section{DISCUSSION}

There was a significant difference in the number of bamboo galls on culms. This could be due to asynchronism of adult emergence of $A$. rhopaloides and bud-burst of branches where females lay eggs (Shibata, 2003).

Spatial distribution is an important aspect of the

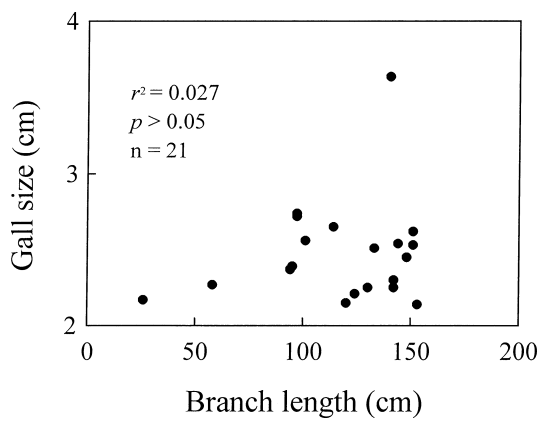

Fig. 4. Relationship between branch length and gall size. Data are based on galls from which $A$. rhopaloides emerged.



Fig. 3. Relationships between branch length and bud length (a), and between branch length and nitrogen content (b). Left: 13 May, right: 1 July. 
population structure and is determined by the intrinsic properties of the species and its habitat (Iwao, 1970). The spatial distribution of insects is not usually random, but is often contagious due to the uneven quality of habitats (Kuno, 1986). In this study, more bamboo galls were formed on longer branches, explaining that the galls are distributed contagiously. Kuno (1986) pointed out that oviposition behavior also contributes to contagious distribution.

More galls are found on longer branches in other galling insects such as sawflies (e.g., Price, 1991; Price and Ohgushi, 1995) and cynipid wasps (e.g. Caouette and Price, 1989; Pires and Price, 2000; Ito and Hijii, 2001) as presented in this study, suggesting the possibility that the module size plays some part in oviposition site preference by female A. rhopaloides and that they utilize larger branches more frequently. However, there was no significant difference in the survival rates of $A$. rhopaloides among branch-length classes like in Andricus moriokae (Hymenoptera: Cynipidae) (Ito and Hijii, 2004). This is different from the sawflies, where survival rates increased with branch length (e.g., Price, 1991; Price and Ohgushi, 1995). Thus, the selection of longer branches for oviposition does not cause better offspring survival in $A$. rhopaloides.

For gall insects, reproductive success and larval survival depend on successful oviposition in plant tissue that is suitable for production of nutritious galls (Abrahamson and Weis, 1987). On 13 May when the bud elongated and female A. rhopaloides oviposited (Shibata, 2001), no significant relationship was found between the branch length and nitrogen content, suggesting that longer braches do not have a higher nutritional content than shorter ones. On 1 July when the larvae of $A$. rhopaloides were developed in the galls (Shibata and Ito, 2005), there was no significant relationship between the branch length and nitrogen content. Thus, the selection of buds on longer branches for oviposition cannot be an adaptive consequence, at least, to increase the offspring survival.

Gall size varies with the gall position on the host plant (Sitch et al., 1988; Ngakan and Yukawa, 1997). The size of the bamboo gall can be a good predictor for potential fecundity because potential fecundity is positively correlated with gall diameter (Shibata, 2002), suggesting that production of larger females from larger galls might improve fitness. However, galls on longer branches were not significantly larger than galls on the shorter branches, suggesting that oviposition on longer branches might not increase the progeny number, or fitness of offspring.

Thus, the preference of female A. rhopaloides for longer branches as an oviposition sites might not increase fitness. Inbar et al. (2001) emphasized that experiments on growth, chemical defense and nutrition of plants might be needed as evidence for the plant-vigor hypothesis. I did not study chemical defense by the bamboo bud against oviposition, and more field experiments on this are needed.

There are two possible reasons why female $A$. rhopaloides might prefer longer branches for oviposition. There was a positive correlation between branch length and bud length on 13 May, but bud length tended to be constant on 1 July. This indicates that bud elongation was more advanced on larger branches than on shorter branches. Shibata (2001) found that A. rhopaloides emerging from galls from mid-April to early May when bamboo buds elongate and the phenology of bamboo might be important for the population dynamics of this insect as a bottom-up effect. A. rhopaloides is proovigenic; emerging females have ca. 80 eggs in their ovaries, suggesting that they can oviposit soon after emergence (Shibata, 2002). It is possible that females oviposit on longer branches because bud elongation and oviposition coincide on longer branches. Thus, the difference in branch phenology in relation to length might affect oviposition site preference.

In this study, the percentage of buds with galls in each branch-length class was nearby constant, suggesting that branch length does not affect the selection of branches when females search buds for oviposition. In addition, longer branches have more buds for oviposition. Thus, female adults might select branches based on the number of buds. In a bamboo stand, there are more branches and buds at heights from 2 to $5 \mathrm{~m}$, so females oviposit on longer branches not because this increases offspring performance but simply because larger branches with more buds allow effective oviposition.

\section{ACKNOWLEDGEMENTS}

I thank K. Kamijo for insect identification, and M. Ito and 
N. Ikai for invaluable suggestions. I also thank M. Suzuki for chemical analysis. Thanks are also due to the members of the Laboratory of Forest Protection, Nagoya University, for their help with the fieldwork. This study was supported in part by a Grant-in-Aid for Scientific Research (No. 11460068) from the Ministry of Education, Culture, Sports, Science and Technology, Japan.

\section{REFERENCES}

Abrahamson, W. G. and A. E. Weis (1987) Nutritional ecology of arthropod gall makers. In Nutrition Ecology of Insects, Mites, Spiders, and Related Invertebrates (F. Slansky, Jr. and J. G. Rodriguez eds.). John Wiley \& Sons, New York, pp. 235-258.

Caouette, M. R. and P. W. Price (1989) Growth of Arizona rose and attack and establishment of gall wasps Diplolepis fusiformans and D. spinosa (Hymenoptera: Cynipidae). Environ. Entomol. 18: 822-828.

Inbar, M., H. Doostdar and R. T. Mayer (2001) Suitability of stressed and vigorous plants to various insect hervivores. Oikos 94: 228-235.

Ito, M. and N. Hijii (2001) Effect of shoot size and phenological variation of host plants on the spatial patterns of cynipid galls. J. For. Res. 6: 147-151.

Ito, M. and N. Hijii (2004) Relationships among abundance of galls, survivorship, and mortality factors in a cynipid wasp, Andricus moriokae (Hymenoptera: Cynipidae). J. For. Res. 9: 355-359.

Iwao, S. (1970) Problems of spatial distribution in animal population ecology. In Random Counts in Biomedical and Social Sciences. Random Counts in Scientific Work. Vol. 2 (G. P. Patil ed.). The Pennsylvania State University Press, University Park and London, pp. 117-149.

Kobayashi, F. (1994) Bamboo gall chalcid. In Forest Insects (F. Kobayashi and A. Taketani eds.). Yokendo, Tokyo, pp. 523-524.

Kuno, E. (1986) Research on Animal Populations. 1. Density Estimation Method. Kyoritsu-Shuppan, Tokyo. 114 pp. (in Japanese).

Morisita, M. (1959) Measuring of the dispersion of individuals and analysis of the distribution patterns. Mem. Fac. Sci., Kyushu Univ., Ser. E (Biol.) 2: 215-235.

Ngakan, P. O. and J. Yukawa (1997) Synchronization with host plant phenology and gall site preference of Dinipponaphis autumna (Homoptera: Aphididae). Appl. Entomol. Zool. 32: 81-90.

Norussis, H. J. (1993) SPSS for Windows. release 6.01. SPSS, Chicago, IL.

Pires, C. S. S. and P. W. Price (2000) Patterns of host plant growth and attack and establishment of gall-inducing wasp (Hymenoptera: Cynipidae). Environ. Entomol. 29: $49-54$.

Price, P. W. (1991) The plant vigor hypothesis and herbivore attack. Oikos 62: 244-251.

Price, W. P., T. P. Craig and H. Roininen (1995) Working toward theory on galling sawfly population dynamics. In Population Dynamics (N. Cappuccino and P. W. Price eds.). Academic Press, New York, pp. 321-338.

Price, P. W., G. W. Fernandes and G. L. Waring (1987) Adaptive nature of insect galls. Environ. Entomol. 16: $15-24$.

Price, P. W. and T. Ohgushi (1995) Preference and performance linkage in a Phyllocolpa sawfly on the willow, Salix miyabeana, on Hokkaido. Res. Popul. Ecol. 37: 23-28.

Rehill, B. J. and J. C. Schultz (2001) Hormaphis hamamelidis and gall size: a test of the plant vigor hypothesis. Oikos 95: 94-104.

Shibata, E. (2001) Synchronization of shoot elongation in the bamboo Phyllostachys heterocycla (Monocotyledoneae: Gramineae) and emergence of the gall maker Aiolomorphous rhopaloides (Hymenoptera: Eurytomidae) and its inquiline Diomorus aiolomorphi (Hymenoptera: Torymidae). Environ. Entomol. 30: 10981102.

Shibata, E. (2002) Potential fecundity of the bamboo gall maker, Aiolomorphus rhopaloides (Hymenoptera: Eurytomidae), and its inquiline, Diomorus aiolomorphi (Hymenoptera: Torymidae), in relation to gall size and body size. J. For. Res. 7: 117-120.

Shibata, E. (2003) Sampling procedure for density estimation of bamboo galls induced by Aiolomorphus rhopaloides (Hymenoptera: Eurytomidae) in a bamboo stand. J. For. Res. 8: 123-126.

Shibata, E. and M. Ito (2005) Life-history traits in insect inclusions associated with bamboo galls. Insect Science 12: $143-150$.

Sitch, T. A., D. A. Grewcock and F. S. Gilbert (1988) Factors affecting components of fitness in a gall-making wasp (Cynips divisa Hartig). Oecologia 76: 371-375.

Takahashi, F. and K. Mizuta (1971) Life cycles of a Eurytomid wasp, Aiolomorphous rhopaloides, and three species of wasps parasitic on it. Jpn. J. Appl. Entomol. Zool. 15: 36-43 (in Japanese with English summary).

Yukawa, J. and H. Masuda (1996) Insect and Mite Galls of Japan in Colors. Zenkoku Noson Kyoiku Kyokai, Tokyo. 826 pp. (in Japanese). 